\title{
A CIDADE COMO PROJETO COLETIVO: impressões sobre a experiência de Medellín
}

\section{Lúcia Maciel Barbosa de Oliveira*}

\section{Resumo}

Reflete-se sobre a possibilidade de recriação da ideia de cidade como projeto coletivo a partir de impressões da experiência de Medellín, Colômbia, ainda em processo, que tem conseguido criar uma nova trama urbana e cidadã em decorrência de um projeto de concertação que tem a cultura como eixo de sua ação.

Palavras-chave: Cidade de reconhecimento. Política cultural. Cultura comum. Sociedade civil. Estado.

A população urbana mundial superou a rural em 2008, segundo dados da Organização das Nações Unidas, sendo que um terço dela vive em favelas. A estimativa é que em 2020 a pobreza urbana do mundo chegue a quase cinquenta por cento dos moradores das cidades. Em 2050, a projeção é que sessenta e cinco por cento da população mundial - estimada em 9 bilhões de pessoas - viva em cidades ${ }^{1}$. Indicadores sombrios, que apontam para o crescimento da violência, da desigualdade, das tensões, da intolerância, da indiferença.

A obsessão maníaca por segurança, a angústia e o medo que assolam os moradores das cidades são a tônica dominante. Segregação, ausência de espaço público, esvaziamento da vida coletiva, sentido de passagem e não de permanência, não pertencimento. Como ressuscitar a ideia da cidade como espaço fundamental da experiência humana, propiciadora de contatos e intercâmbios? Como repropor a cidade como projeto coletivo?

\footnotetext{
*Graduada em História, Mestre em Ciências da Comunicação e Doutora em Ciência da Informação pela Universidade de São Paulo. Professora da Universidade de São Paulo. E-mail: lumaneo@ajato.com.br

${ }^{1}$ Ver Relatório das Nações Unidas. Acessível em:

<http://unstats.un.org/unsd/demographic/products/dyb/dyb2008.htm>. Acesso em 30 ago. 2011.
} 
Traçar e redesenhar a vida cotidiana, a esfera pública e novos modos de usar a cidade são talvez os maiores desafios colocados aos sujeitos e coletividades.

No instante em que se fala à exaustão das cidades do conhecimento e das cidades do desconhecimento, como construir cidades do reconhecimento? - como sublinhou Néstor Canclini $^{2}$ - Como propor a radicalidade de um projeto coletivo?

\section{Espaço público x espaço privado}

A definição de espaço público como o que se opõe ao privado, ou seja, a contraposição do lugar do eu individual (a casa) àquele coletivo (a rua) parece ser o conceito dominante na atualidade. A ideia fundamental de que o espaço público é bem mais do que apenas a oposição ao privado na medida em que é o lugar da construção do 'nós comum’ como sinônimo de comunidade, como espaço da solidariedade entre a coletividade, parece não fazer nenhum sentido. Henry Lefebvre (2001) em seu livro O direito à cidade, defende a ideia de que a vida urbana pressupõe encontros, confrontos das diferenças, reconhecimentos recíprocos: o direito à vida urbana diz respeito à apropriação da cidade como lugar que se habita, como obra de participação e criação coletiva.

Zigmunt Bauman (2009) aponta que o medo e a insegurança que vivemos hoje nas cidades têm gerado nos indivíduos a tendência a retirar-se dos espaços públicos para refugiarse em ilhas de uniformidade, o que acaba se transformando numa imensa barreira que impede a convivência das diferenças, enfraquecendo os diálogos e os pactos sociais. Ao mesmo tempo, as cidades contemporâneas converteram-se em campos de batalha na luta travada entre poderes globais e os sentidos e identidades 'tenazmente locais', confronto que orienta a dinâmica das cidades na atual configuração do mundo. O pânico que parece tomar conta de muitos habitantes das cidades em seu confronto com 'estrangeiros', sejam eles oriundos de outros lugares ou apenas indivíduos não reconhecidos como semelhantes, leva a segregações nem sempre metafóricas: barreiras físicas que separam grupos determinando novas concepções no traço urbano, na guetificação e no isolamento das pessoas. Segregação e exclusão são um binômio inseparável na nova configuração das cidades. As pontes estão sendo demolidas e não há desejo de mantê-las ou construí-las. Bauman destaca a crescente mixofobia, o medo de misturar-se, como consequência da desintegração crescente da vida

\footnotetext{
${ }^{2}$ Ver CANCLINI, N.G. Imaginários culturais da cidade: conhecimento/espetáculo/reconhecimento. In. COELHO, J.T. (org). A cultura pela cidade. São Paulo: Iluminuras/Itaú Cultural, 2008, p.15-31.
} 
comunitária, o que gera o impulso à segregação em ilhas de identidade e semelhança. Em suas palavras:

\begin{abstract}
Essa mixofobia não passa da difusa e muito previsível reação à impressionante e exasperadora variedade de tipos humanos e de estilos de vida que se podem encontrar nas ruas das cidades contemporâneas e mesmo na mais "comum" (ou seja, não protegida por espaços vedados) das zonas residenciais. Uma vez que a multiforme e plurilinguística cultura do ambiente urbano na era da globalização se impõe - e, ao que tudo indica, tende a aumentar -, as tensões derivadas da "estrangeiridade" incômoda e desorientadora desse cenário acabarão, provavelmente, por favorecer as tendências segregacionistas (2009: 43).
\end{abstract}

A reversão desse quadro segregador só será possível a partir de experiências compartilhadas em espaços urbanos. (Re) Construir espaços públicos que propiciem encontros interculturais, abertos a todos como indivíduos anônimos que não precisam de identificação e não são identificados a priori, mas como singularidades, como componentes de uma multiplicidade de singularidades. "Espaços públicos são locais em que atração e rejeição se desafiam (...) Os locais públicos são os pontos cruciais nos quais o futuro da vida urbana é decidido neste exato momento”, ou seja, no confronto direto da diversidade, das diferenças, expondo desigualdades. "São esses espaços públicos que, reconhecendo o valor criativo das diversidades e sua capacidade de tornar a vida mais intensa, encorajam as diferenças a empenhar-se num diálogo significativo” (BAUMAN, 2009:70-71).

A ação coletiva concretiza-se no espaço da cidade, espaço de encontros e confrontos, em que se criam redes de convivência e de comunicação. O processo de globalização que transborda fronteiras, gera desterritorializações e deslocamentos, enfatiza a diversidade e acentua as diferenças de culturas e modos de vida, fortalecendo, de modo paradoxal, as políticas de proximidade, locais, pela ação e pressão direta dos sujeitos que dela participam. A maior parte das necessidades dos indivíduos se encontra na dimensão local e é ali que as soluções devem ser procuradas, experimentações podem ser propostas e concretizadas. As tecnologias da informação têm potencializado os processos sociais a distância, propiciado encontros entre seres distantes fisicamente, tornando os espaços de intercâmbio mais complexos na esfera próxima. As redes não são apenas propiciadoras de compartilhamentos e encontros; favorecem também as relações ligadas à legalidade e à ilegalidade, ao lícito e ao ilícito, o que esgarça ainda mais o frágil tecido urbano, impedindo o fortalecimento de uma real cultura política. 
Voltando às considerações de Canclini (2008), as cidades não existem apenas como ocupação territorial e interações materiais entre indivíduos, mas dizem respeito a uma larga dimensão simbólica, novas cartografias mentais e culturais, o que determina uma tensão constante entre o que são as cidades e o que gostaríamos que fossem. Como construir cidades do reconhecimento que permitam a configuração de um projeto coletivo ao mesmo tempo em que respondam à dimensão imaginária dos indivíduos que nelas habitam?

\section{Refazendo tramas}

Medellín chegou a ser a cidade mais violenta do mundo na década de 1990. Capital do Departamento de Antioquia, Medellín é a segunda cidade mais populosa da Colômbia. Como em tantas outras cidades do planeta, concentra uma alta densidade populacional espalhada de maneira não uniforme pelo vale e morros que caracterizam sua topografia, grande parte ocupada de maneira desordenada e sem infraestrutura urbana adequada.

O intenso processo de urbanização da cidade deu-se a partir da década de 1950, como em outras cidades da América Latina, inclusive no Brasil. O afluxo de pessoas iniciado nesse período deveu-se, sobretudo, a um violento processo ocorrido na Colômbia, denominado La Violencia. Tal episódio caracterizou-se por uma intensa e longa luta armada entre facções identificadas com os partidos políticos tradicionais - Liberais e Conservadores -, pelo domínio das zonas menos urbanizadas do país e pelo controle dos cargos públicos pela classe política. Populações foram armadas para o combate e um longo período de violência assolou o país. Em 1958 os partidos pactuaram a paz mediante um acordo de alternância no poder e a divisão equânime da burocracia pública. A Frente Nacional (1958-1974), como foi denominado o pacto, determinou um período de intenso crescimento econômico na Colômbia, além de ter sido uma estratégia de grupos detentores de poder político contra o crescente poder dos bandoleiros, guerrilheiros e grupos armados que, chamados a participar no conflito anterior, ficaram à margem na nova configuração política. A luta travada nas zonas menos urbanizadas gerou a fuga da população dessas áreas e o consequente inchaço das cidades com os camponeses refugiados, que passaram a ocupar os morros da cidade com suas habitações precárias, sem infraestrutura urbana, sem oferta institucional nem empregos formais, iniciando um longo processo de exclusão. Os desplazados (deslocados) passam a constituir a população que ocupa os morros de maneira crescente. Esse deslocamento interno forçado trouxe, como consequência, uma implacável espiral de violências e vinganças vividas por 
várias gerações, o esgarçamento do tecido social e um sentido de não pertencimento impeditivo da construção de uma esfera pública substantiva. Segundo a socióloga Elsa Blair, coordenadora do núcleo de Cultura, Violência e Território da Universidade de Antioquia, diferentemente de outros países como Ruanda e Guatemala, que também sofreram processos intensos de deslocamentos internos forçados, a peculiaridade colombiana é a multiplicidade dispersa de correntes isoladas. Daí resulta que indivíduos e famílias optam pela fuga ante ameaças de morte e buscam refúgio por sua conta e risco, já que não existem espaços de recepção coletiva, como os campos de refugiados, nem existiam políticas governamentais até 1995 - período de recrudescimento da violência com a luta travada entre o Estado e os paramilitares, os narcotraficantes e os guerrilheiros -, quando se formulou pela primeira vez uma política emergencial de assistência, frágil e incorporada às políticas de desenvolvimento. A possibilidade de construção de uma cultura comum, de criação de sentido de pertencimento, de espaços públicos democráticos, de refação do tecido social totalmente desfeito, estava longe de consubstanciar-se, sobretudo pela postura governamental de confronto e exacerbação do conflito, ou seja, perseguição e violência a indivíduos e grupos, sem atacar a raiz do problema.

A população espremida nos morros, sobretudo os homens jovens e sem maiores perspectivas de vida, organizou-se em grupos armados majoritariamente pelos cartéis de drogas: gangues juvenis, paramilitares e guerrilheiros. A disputa por controle local, consubstanciada em lutas pelo poder em comunidades onde o Estado colapsou, determina o aumento da violência e o crescente número de mortes, sobretudo entre jovens de 14 a 21 anos, que chega ao seu auge em Medellín no início da década de 1990: 381 mortes por 100 mil habitantes segundo dados da prefeitura ${ }^{3}$.

Algumas ações começam a mudar este quadro. Em 2003, ocorre o processo de desmobilização do grupo paramilitar denominado Bloque Cacique Nutibara, que, constituído como programa nacional, ganha ações substanciais em Medellín como Programa Paz y Reconciliación, incluído no Plan de Desarrollo de Medellín 2004-2007. O Bloque Cacique Nutibara, nascido em 2001 sob o comando de Diego Murillo, conhecido como Don Berna, objetivava o controle hegemônico sobre os bairros periféricos e o centro da cidade por meio do monopólio da força e da coerção sobre os territórios onde havia gangues e milícias. Logo dominaram o mercado de segurança dessas zonas, protegendo a economia ilegal e inserindo-

\footnotetext{
${ }^{3}$ Dados extraídos da publicação produzida pela Alcaldía de Medellín (2008). Del miedo a la esperanza. Medellín. Colômbia.
} 
se na vida cotidiana das comunidades por meio de um violento controle social, de negócios legais e ilegais, lícitos e ilícitos.

O Programa de regresso à legalidade levado a cabo pela administração de Sérgio Fajardo (2004-2007) foi pioneiro em processos de paz negociada e reinserção de indivíduos que se encontravam à margem do Estado. O programa nacional previa um prazo de dezoito meses para o processo de regresso, tempo considerado insuficiente pela prefeitura de Medellín, tendo sido ampliado de maneira indefinida para cada indivíduo pelo apoio integral e não apenas laboral: albergue, assistência psicológica e financeira, estendida às famílias, cursos profissionalizantes, busca de empregos e acompanhamento continuado na função por meio de um acordo com o setor empresarial. As oitocentas e sessenta e oito pessoas inicialmente incluídas no Programa passaram a quatro mil e duzentas com sua extensão a outros grupos de Medellín a partir de $2005^{4}$, sendo o índice de reincidência ou morte por assassinato inferior a vinte por cento. Este programa é fundamental para compreender os projetos implantados a partir da gestão de Sérgio Fajardo à frente da prefeitura.

\section{Do contexto da nova gestão}

A Colômbia promulgou uma nova constituição em 1991, o que determinou uma reestruturação política, descentralizada, municipalizada, dando mais poder e autonomia aos municípios, inclusive com a eleição direta para prefeitos e governadores. Abre-se uma perspectiva mais democrática para a gestão das cidades ${ }^{5}$.

Em 2004 é eleito Sérgio Fajardo, matemático, professor da Universidade de Los Andes e Nacional, em Bogotá, natural de Medellín, que havia concorrido à prefeitura nas eleições de 2000, mas fora derrotado por Luís Pérez Gutiérrez. Na eleição seguinte sai vitorioso. A peculiaridade da candidatura de Fajardo foi de ter se dado fora das estruturas políticas tradicionais, através de uma concertação entre diferentes atores independentes, sem vínculos com partidos políticos, instrumento previsto na constituição do país desde que a candidatura seja apoiada por um número expressivo de pessoas que se manifestam por uma

\footnotetext{
${ }^{4}$ Idem

${ }^{5}$ Segundo a Agenda 21 da Cultura - documento orientador das políticas públicas de cultura e contribuição para o desenvolvimento cultural da humanidade, aprovado em Barcelona em 2004, - as cidades assumem papel protagonista nas políticas públicas de cultura, e sua gestão deve se pautar pelo princípio da subsidiaridade, ou seja, aquele que determina que os assuntos devam ser tratados, sempre que possível, pela autoridade mais baixa, de forma que os instrumentos estatais de satisfação dos interesses da sociedade estejam o mais próximo possível dos indivíduos. Medellín teve papel protagonista na elaboração da Agenda 21 e segue ativa em sua implantação. Apesar da Agenda 21 voltar-se para as políticas de cultura, esta é entendida como instância central das políticas públicas para o desenvolvimento humano pensado de maneira integral.
} 
lista de assinaturas. Segundo publicação que auto-avalia a gestão de Fajardo à frente da prefeitura,

en el contexto político que comenzó con la elección popular de alcaldes, nuestra presencia es una ruptura significativa pues es la primera vez que un movimiento cívico-independiente llega al poder, por fuera de la estructura política tradicional, en cabeza de partidos políticos deteriorados, con una gran pérdida de credibilidad y ascendencia sobre la ciudadanía, incapaces de dar respuestas a las necesidades y aspiraciones de la gente. Lo cual, es justo señalar, tampoco significa que en esos partidos no hayamos tenido y tengamos personas muy valiosas. Pero sí es obvio que de la mano de una forma nueva y coherente de hacer la política, con una visión diferente de la sociedad, surja una forma distinta de la gestión pública y la dirección en la que se mueve la ciudad sea otra (Alcaldía. 2008: 7).

O movimento independente denominado Compromiso Ciudadano, que teve início com cinquenta pessoas oriundas da universidade, de organizações não governamentais, do empresariado, do setor cultural e do setor social, todas desvinculadas de partidos políticos, traçou como objetivo claro chegar ao poder para mudar a cidade e reverter o quadro de violência, a ausência de uma cultura pública e a falta de perspectiva para a cidade e seus habitantes. A proposta de mudança partia da ideia de uma gestão não hierarquizada, adensada com a primeira campanha para as eleições que abriu caminho para a inserção do grupo na esfera pública. O processo de campanha foi uma experiência em si transformadora, na medida em que se baseava em um diálogo com as pessoas e comunidades visitadas. O canal foi aberto e permitiu uma vitória expressiva nas eleições seguintes. Um dos eixos principais era a total transparência na gestão dos recursos públicos, nenhuma concessão à corrupção e ações voltadas às áreas mais abandonadas pelo poder público até então: as regiões com menor índice de desenvolvimento humano (IDH) e índice de qualidade de vida (ICV) ${ }^{6}$ seriam privilegiadas, de maneira que a estrutura institucional chegasse àquelas áreas onde o Estado havia colapsado ${ }^{7}$. A busca de reversão do quadro de desigualdade em todas as esferas,

\footnotetext{
${ }^{6} \mathrm{O}$ IDH se refere à medição de três dimensões essenciais da existência humana: viver, saber e ter os meios para os gastos básicos. O ICV mede variáveis relacionadas à moradia e entorno, serviços públicos e saneamento básico, composição familiar e níveis de educação.

${ }^{7}$ Tão logo chegou ao poder, o grupo lançou um documento com os 14 princípios da gestão pública. São eles:

1. Los dineros públicos son sagrados.

2. La gestión de lo público es transparente. La Administración rinde cuentas de todo lo que hace, con quién lo hace, cuándo lo hace, cómo lo hace y con cuánto lo hace.

3. No aceptamos transacciones de poder político por intereses burocráticos o económicos.

4. No utilizamos el poder del Estado para comprar conciencias y acallar opiniones diferentes a las nuestras.

5. El ejemplo de las autoridades es la principal herramienta pedagógica de transformación cívica.

6. Planeación sin improvisación.

7. Eficiencia, economía y eficacia en los programas y proyectos.
} 
característica dos países latino-americanos (embora não seja exclusividade regional), teve suas ações centradas em áreas como a educação, a cultura e, fundamental, a informação, fator de exclusão das parcelas menos privilegiadas da sociedade, criando abismos cada vez maiores entre pessoas e grupos. A inclusão digital foi e segue sendo um eixo primordial de ação na cidade.

No livro The wealth of network (2006), Yochai Benkler defende que a informação, o conhecimento e a cultura são elementos centrais para o desenvolvimento da liberdade humana, hoje mais do que nunca. A forma como esses elementos são produzidos e intercambiados em nossa sociedade afeta de maneira crítica o modo como vemos o estado do mundo e como imaginamos que possa vir a ser. O acesso à cultura, à informação e ao conhecimento tornou-se indispensável não somente no mundo do trabalho, mas para o fortalecimento da cidadania, para a produção cultural e artística, para o desenvolvimento dos indivíduos de maneira ampla. As novas tecnologias de informação e comunicação ampliam a possibilidade de ação dos sujeitos que passam a ser não apenas leitores e receptores, mas produtores de informação. Mais importante do que a conectividade técnica é a capacidade educativa e cultural de utilizar a informação, o que significa saber buscá-la e transformá-la em conhecimento para aquilo que se deseja. A informação pode ser tanto fator de dominação quanto de emancipação. A diminuição da enorme divisão social que separa indivíduos, grupos e países, passa necessariamente, hoje, pela inclusão digital. O projeto de Medellín focou-se de maneira enfática neste eixo de ação. Dados de 2007 apontam que, 450 mil pessoas passaram a ter acesso à internet (o que significa um quarto da população), 61 instituições educativas foram dotadas de acesso (com liberação de uso fora dos horários de aula e nos finais de semana), 11 centros de navegação foram criados, 10 'Punto Común’ em zonas de baixa cobertura em conexão digital, salas de navegação nos Parques Biblioteca, 700 computadores na Rede de Bibliotecas, 350 computadores portáteis para crianças nos Parques Biblioteca, 12 mil computadores com banda larga, 5 mil computadores adicionais em instituições

8. Las relaciones con la comunidad son abiertas y claras, y se desarrollan a través de los espacios de participación ciudadana.

9. El interés público prevalece sobre los intereses particulares.

10. Las personas que trabajan en la Administración Municipal son honestas, capaces y comprometidas con el proyecto de ciudad.

11. El desarrollo de la ciudad es un compromiso entre la Administración local y toda la ciudadanía.

12. La solidaridad y la cooperación son la base de las relaciones de la ciudad con la región, el departamento, la nación y la comunidad internacional.

13. La confianza entre las personas que dirigen la Administración es esencial para garantizar la legitimidad del Estado.

14. La vida es valor máximo y no hay una sola idea ni propósito que ameriten el uso de la violencia para alcanzarlos. 
educativas, 3 mil docentes capacitados em informática, além dos micro-ônibus digitais, que percorrem zonas não atendidas pelos outros programas ${ }^{8}$. Informação como fio que tece o conhecimento e a cultura. Voltaremos a essa questão posteriormente.

Outra esfera fundamental para a consolidação de uma gestão transparente e com participação ativa da sociedade civil $^{9}$ foi o fortalecimento da comunicação pública, pensada de maneira integral; em outras palavras, não a mera informação fragmentada em que cada secretaria se ocupava de suas ações, mas a comunicação como eixo central de uma gestão democrática que deve prestar contas de suas ações de maneira global e coerente, além da obrigatoriedade de ser facilmente compreendida por toda a população. A criação da Redcom, Rede de Meios Comunitários, buscou capacitar as pessoas como produtoras de conteúdos, fortalecendo a comunicação comunitária autônoma e independente, inserindo a comunicação como esfera central das políticas públicas.

Os principais programas desenvolvidos ao longo da gestão de Sérgio Fajardo à frente da prefeitura - que continuam em processo a partir da gestão seguinte de Alonso Salazar, sucessor que participou da gestão anterior - são: Cultura do Empreendimento, Orçamento Participativo, Urbanismo Social e Projetos Urbanos Integrais, Medellín Inclusiva, além da intervenção maciça no sistema educacional.

O orçamento participativo pode ser percebido como um processo transformador em si: busca formar competências individuais e coletivas por meio de uma ação participativa que redireciona práticas políticas consolidadas para ações diretas que deflagram processos transformadores, geram autonomia, determinam a construção de espaços públicos democráticos, empoderam ${ }^{10}$ indivíduos e grupos, exercitam a resolução de conflitos. A cultura do empreendimento voltada, sobretudo para populações, em larga medida, sem empregos formais nem capacitação profissional, traz benefícios inclusivos diretos. Para a descentralização das ações e ampliação do acesso ao programa, foram criados os CEDEZOS Centros de Desarrollo Empresarial Zonal -, localizados em diferentes partes da cidade, inclusive nos cinco Parques Biblioteca, de maneira a que as pessoas possam solicitar cursos capacitadores em gestão de empresas, cursos técnicos relativos à área do empreendimento que

\footnotetext{
${ }^{8}$ Dados extraídos da publicação da Alcaldía de Medellín. Del miedo a la esperanza. Medellín, 2008.

${ }^{9}$ Segundo a definição proposta por Cohen e Arato, sociedade civil é una esfera de interacción social entre la economía y el Estado, compuesta ante todo de la esfera íntima (en especial la familia), la esfera de las asociaciones (en especial las asociaciones voluntarias), los movimientos sociales y las formas de comunicación pública. La sociedad civil moderna se crea por medio de formas de autoconstitución y automovilización. (2001: 8)

${ }^{10}$ Empoderar, neologismo originado da palavra inglesa empowerment, significa dar poder, autonomia e espaço de participação aos sujeitos e grupos deles desprovidos.
} 
querem desenvolver, além do acesso ao microcrédito por intermédio da Red de Microcrédito. Tais ações têm levado renda a regiões da cidade sem perspectivas anteriores.

Para o cientista político uruguaio Gerardo Caetano, o grande desafio de uma reinvenção da cidadania, mais do que nunca necessária, é a participação da sociedade civil de maneira efetiva:

se não se quer que os programas de emergência se tornem assistencialistas, mas comecem a atacar as estruturas de exclusão, é imperativo que os beneficiários das novas políticas públicas se tornem, de modo crescente, sujeitos e não simples objetos da ação pública (2007: 46).

Necessário, nessa perspectiva, pensar a cidade como uma rede, de maneira rizomática e não arborescente como as estruturas de poder tendem a fazer. O rizoma é aberto, como anotam Deleuze e Guattari, conectando um ponto qualquer com outro ponto qualquer, sem que tenham traços da mesma natureza: um mapa que deve ser produzido, construído, sempre desmontável. (1996: p.32) A sociedade civil e o Estado devem tecer redes que consubstanciem a ideia da cidade como projeto coletivo, processo compartilhado em contínua ação. Marco Aurélio Nogueira, ao refletir sobre o Estado e a sociedade civil na atualidade, sublinha que a participação não é mais pensada como o reverso da representação ou como veículo privilegiado da pressão popular em estruturas democráticas, mas como a expressão de práticas sociais democráticas interessadas em superar os gargalos da burocracia pública e em alcançar soluções positivas para os diferentes problemas comunitários (2004: 121). Ainda segundo ele, o Estado hoje deve ser pensado da e para a sociedade civil, o que aproxima o tema da participação e da democracia à questão da reforma do Estado prolongamento de uma reforma democrática e social - e da ampliação da noção de espaço público (idem: 120). O Estado é indispensável, defende Nogueira, como condição para a autonomia e potência da democracia e da sociedade civil (ibidem: 67).

Os Projetos Urbanos Integrais (PUI) configuram uma ação de impacto em zonas abandonadas pelas políticas públicas. São gerados a partir da participação coletiva em comunidades com graves problemas estruturais, de confronto e disputa de territórios, com total ausência de políticas públicas.

Las comunidades participan en cada etapa del proceso y se convierten en protagonistas de su desarrollo. Con ellas se definen los problemas que se deben resolver, ellas se sueñan en talleres de "imaginarios" su desarrollo futuro y los proyectos, y luego es su fuerza de trabajo la que construye los nuevos espacios, edificios y puentes. Al final, las personas cuidan y disfrutan 
estos PUI espacios en los que se encuentran porque son producto de sus sueños. (Alcaldía, 2008: 68)

Há um longo caminho de chegada a esses grupos, absolutamente descrentes da ação pública, por meio de processos de paz e reconciliação consubstanciados em um projeto de concertação, necessariamente coletivo. As mesas de trabalho envolvendo diferentes grupos, as oficinas, trabalhos com artistas, entre outros, procuram legitimar o projeto e atrair a população dos bairros para o desenho das ações a serem desenvolvidas, visando, em última instância, aumentar o desenvolvimento humano, melhorar a confiança na ação política e diminuir a violência. Os projetos urbanos integrais são definidos como projetos urbanos que incorporam todos os elementos do desenvolvimento de forma planejada e simultânea em um território pré-estabelecido, com participação ativa da população local, em bairros com problemas profundos. Em outras palavras, um projeto estratégico articulador que significa uma grande ação no espaço público, uma intervenção maciça em um bairro a partir de grandes obras de infraestrutura, buscando integrá-lo à cidade. Para a escolha das localidades beneficiárias das intervenções é utilizado o IDH - Índice de Desenvolvimento Humano, como critério público, transparente e não clientelista de distribuição do orçamento entre os diferentes bairros, sendo a dotação orçamentária maior para os bairros com menor IDH. Procura-se promover alianças com diferentes atores: setor privado, ONGs, organismos nacionais e internacionais, organizações comunitárias já presentes, de forma a viabilizar o projeto em todos os sentidos. A ação se dá em vários eixos: saneamento; pavimentação das ruas; iluminação pública; transporte urbano - complementado pelos metrocables, teleféricos interligados ao metrô, que levam aos bairros mais íngremes; praças e outros espaços públicos; escolas de excelência (Colegios de Calidad, como são denominados); centros de saúde; construção de moradias populares em alguns bairros; recuperação do meio ambiente; geração de emprego e fortalecimento do comércio local; quadras esportivas e os Parques Biblioteca, de que falaremos a seguir.

\section{A cultura como instância central das políticas públicas}

Os Parques Biblioteca estão inseridos no plano de desenvolvimento traçado para a cidade cujo eixo de ação delineia-se a partir do conceito de Medellín como cidade com alto nível cultural em que os setores econômico, político, social, tecnológico e acadêmico devem definir e considerar o conhecimento como o principal capital para o desenvolvimento; entre outras coisas, devem incrementar, aplicar e melhorar o uso da informação para que a 
sociedade tenha instrumentos para resolver e lidar com seus problemas. Tal ação procura gerar uma transformação cultural na maneira de ser, de atuar e de habitar a cidade a partir do sentido de apropriação e de criação de espaços de participação. A cultura ganha espaço substancial nas políticas públicas já que é eixo fundamental para a criação da cidade como projeto coletivo e sua efetiva transformação a partir de outras bases, o que determina o reconhecimento do papel fundamental da cultura na busca de alternativas de futuro e para um desenvolvimento sustentado, essencial para a ampliação da cidadania e para o fortalecimento democrático. A cultura, entendida na perspectiva proposta por Néstor Canclini (2004), como processos sociais de significação, determina um papel central às políticas culturais democráticas que devem criar as condições para a circulação dos diferentes sentidos que os sujeitos e grupos produzem na sociedade, garantindo que tenham espaço de expressão na arena pública.

A transversalidade da cultura nas políticas públicas gera um aumento orçamentário significativo: cinco por cento do orçamento municipal são investidos diretamente no setor. Nessa perspectiva, a cultura passa a ser vista como um componente fundamental da qualidade de vida, do empoderamento da sociedade civil, da inclusão das parcelas excluídas da população e da promoção de novas formas de cidadania. O papel essencial da cultura no planejamento das políticas públicas e na reconfiguração das maneiras como os governos planificam o futuro e avaliam o passado é a perspectiva adotada por Jon Hawkes (2001). Para ele, os quatro pilares da sustentabilidade são hoje: o pilar econômico, relacionado com a criação de riqueza; o pilar social, relacionado à distribuição dessa riqueza; o pilar ecológico, que assegura a responsabilidade sobre o meio ambiente; o pilar cultural, em que a vitalidade cultural é elemento fundamental para a criação de sociedades sólidas, saudáveis e com ampla participação dos cidadãos. Em Medellín a cultura passa a integrar de maneira prioritária as ações públicas de forma inovadora a partir da ideia de que a cultura é um fim em si e não um meio para atingir outros fins, instrumentalização a que assistimos hoje repetidamente. No 'Plan Cultural de Medellín 2010-2020’, ainda em processo de discussão, explicita-se:

La pregunta por la ciudad y la ciudadanía no pueden dejar de lado una gestión cultural que también se pregunta por el habitante, por el sujeto que crea, recrea, produce, consume, disfruta, desea y expresa de manera propia, libre y sin un fin mayor que el de construir y fortalecer su lugar, su visión y su sentido de mundo ${ }^{11}$.

11 Plan Cultural de Medellín 2010-2020. Sistema Municipal de Cultura de Medellín/Alcaldía de Medellín/Universidad de Antioquia. Apresentação em Power Point, 2009. Sobre a cultura e as políticas culturais o plano explicita: 
A criação coletiva de um plano de cultura para a cidade, estruturado a partir da pergunta “¿Cómo desde la cultura si construye ciudad?” significa, em outras palavras, questionar sobre a cidade que vem sendo construída, que cidade se deseja construir e como construí-la a partir da cultura.

Nessa vertente, o Conselho Municipal de Cultura, que já existia de maneira tímida desde $1997^{12}$, passa por um longo processo, ainda em curso, de adensamento e ampliação da participação da sociedade civil para elaboração, execução e acompanhamento das políticas culturais e de planos, projetos e ações para a área cultural. A formulação do plano cultural da cidade baseia-se na democracia participativa e deve corresponder a um processo de construção consensual entre diferentes atores a partir do princípio da diversidade e da interculturalidade. O Conselho Municipal integra o Sistema Municipal de Cultura, ademais composto pelos Conselhos Zonais (as cinco zonas em que é dividida a cidade), os Conselhos Corregimentais (os 6 corregimientos localizados nas áreas ao redor da cidade), Os Conselhos Setoriais (bibliotecas; meios cidadãos e comunitários; patrimônio), os Conselhos Artísticos (artes cênicas; artes da dança; artes plásticas e visuais; literatura; música; artes) e Outras Representações (mesa de artesãos; museus; povos indígenas; comunidades afrodescendentes; ONGs, agremiações ou associações de comunicadores; estabelecimentos de educação superior com extensão cultural; setor de produção, bens e serviços; organizações que trabalham com pessoas com deficiência; conselho municipal da juventude; comunidade educativa; grupos de pesquisa em ciências sociais e humanas com ênfase em arte e cultura). A ampliação da participação no Sistema de Cultura tem sido um processo compartilhado que adensa a proposição das políticas públicas e tem permitido que diferentes atores tenham voz nessa elaboração conjunta. Processo longo e difícil segundo avaliam seus partícipes.

\footnotetext{
'El Plan Cultural de Medellín no agota la cultura ni lo cultural de la ciudad. Es un instrumento de gestión en lo cual la sociedad imprime un pacto sobre lo que quiere desarrollar en tanto su acuerdo de lo cultural para conseguir los objetivos que se propone, en términos prospectivos; pero, también preguntándose como desde él se aporta a la construcción de un proyecto general de ciudad y al fortalecimiento de la ciudadanía que lo permitiría; cuidando además que este sea lo suficientemente flexible para no ahogar otras expresiones y proyectos particulares que no se acuerden dentro de él.'

${ }^{12}$ Muitas das referências sobre a ação da Secretaría de Cultura Ciudadana e do Conselho Municipal de Cultura foram obtidas em entrevistas feitas tanto com a Subsecretaria de Cultura, Maria Rosa Machado, quanto com participantes do Conselho Municipal de Cultura - William Carvajal, Maria Ayde Tamayo e Shirley Milena Zuluaga Cosme, em julho de 2009.
} 


\section{Os parques biblioteca}

Medellín foi pioneira na concepção de bibliotecas desde 1954, quando escolhida pela Unesco, juntamente com Nova Deli, Índia, para receber uma biblioteca pública piloto que posteriormente se expandiria para outras cidades do mundo. Em 2003, com o novo projeto de cidade, as bibliotecas foram interligadas em uma rede e passaram a ser concebidas com funções ampliadas, ou seja, como centros culturais e comunitários que não podem se limitar a prestar os serviços bibliotecários tradicionais e devem oferecer uma multiplicidade de ofertas e atividades buscando melhorar a qualidade de vida e o espaço público onde estão inseridas, além de serem referências fundamentais da estrutura urbanística das suas comunidades, centros de comunicação e cooperação com outras instituições das zonas onde estão localizadas e propiciarem o acesso à informação e à cultura em suas diferentes formas e manifestações, servindo como mediadora na transformação da informação passiva para o conhecimento ativo.

Os Parques Biblioteca consubstanciam-se em ação fundamental para todo o projeto de cidade traçado a partir de 2003. Apesar do nome, constituem-se em grandes centros culturais com projetos arquitetônicos impactantes que têm nas bibliotecas uma área fundamental de ação. Visam construir espaços públicos inclusivos e igualitários, propiciando lugares para o encontro, a educação, a recreação, a cultura e a arte. Os eixos programáticos do projeto, conforme exposto no 'Lineamientos Político Culturales del Plan de Desarrollo Cultural de Medellín 2009-2020’, são:

- Desenvolvimento humano sustentável;

- Diversidade cultural;

- Dimensão social do conhecimento, da informação e da leitura;

- Plataforma tecnológica e conectividade;

- Participação cidadã e comunitária;

- Comunicação para o desenvolvimento e trabalho em rede;

- Empreendimento das comunidades (CEDEZO) + Banco de Microcrédito;

A implantação do projeto é viabilizada pelas verbas da prefeitura e parcerias com o setor empresarial ou instituições internacionais, e sua manutenção é garantida pelas Cajas de Compensación, entidades patronais que recolhem as contribuições das empresas e que devem ser empregadas em projetos sociais, educativos e culturais ${ }^{13}$.

\footnotetext{
13 Segundo entrevista com a Subsecretaria de Cultura de Medellín, María Rosa Machado, realizada em 15/07/2009, a manutenção de cada um dos Parques Biblioteca custa US\$ 1milhão anuais.
} 
Algumas das ações já expostas anteriormente estão inseridas nesse projeto, que oferece também, além do acesso aos serviços bibliotecários e do espaço de convivência, salas de leitura para crianças e adultos; centros de navegação na Internet; empréstimos de DVDs; Ludotecas, ligadas a outro programa da prefeitura denominado 'madres comunitárias', mães que tomam conta de um número pequeno de crianças da vizinhança em sua casa e recebem um salário para essa função; Cedezos e acompanhamento das atividades econômicas das zonas; teatro e salão de exposições (que podem ser requisitados livremente pelas pessoas, fato que merece ser fortemente sublinhado); cafeteria e serviços de cópia, encadernação e papelaria que são explorados por pessoas da comunidade mediante edital público; Salas mi Barrio, destinadas aos encontros dos grupos dos bairros além de fornecerem informações locais, legislação da cidade e guardarem a memória da região. No Parque Biblioteca Belén há uma escola de música para instrumentos de corda (no Centro Cultural de Moravia há outra escola de música para instrumentos de sopro).

Há cinco Parques Biblioteca em funcionamento, com previsão de inauguração de mais cinco. O primeiro a ser inaugurado, em 31 de dezembro de 2006, foi o Parque Biblioteca Presbítero José Luís Arroyabe, conhecido como San Javier, localizado na segunda zona mais densamente povoada da cidade e com total ausência de espaços culturais e comunitários. Em seguida, o Parque Biblioteca León de Greiff, em 17 de fevereiro de 2007, conhecido como La Ladera, que ocupa o terreno de um antigo presídio feminino e está localizado em uma zona com alta concentração de estabelecimentos educativos, mas com total déficit de infraestrutura e equipamentos urbanos. O Parque Biblioteca Tomas Carrasquilla, conhecido como La Quintana, inaugurado em 10 de março de 2007, localizado na zona de maior densidade populacional da cidade, com alto índice de pobreza e déficit crítico de infraestrutura, espaços públicos, equipamentos urbanos e espaços culturais. A ausência de políticas públicas na área era parcialmente preenchida pelos dezenove projetos de bibliotecas comunitárias e privadas que já havia na região. O Parque Biblioteca España, construído em parceria com o governo espanhol, foi inaugurado em 24 de maio de 2007. A zona onde está localizado, carente de equipamentos, apresentava alto índice de violência, concentra mais de vinte e cinco por cento da população da cidade e é composta por pessoas situadas nos estratos econômicos mais baixos. O último Parque Biblioteca a ser construído, Belén, inaugurado em 15 de março de 2008, ocupa o terreno de um antigo batalhão da polícia e é uma parceria com a Universidade de Tokyo e o governo japonês, projeto do arquiteto Hiroito Naito, que doou sua grande biblioteca de livros de arte e arquitetura para o novo projeto. Apesar de situado em uma zona 
com menos carência de infraestrutura e equipamentos, nasceu da pressão da comunidade local, bastante articulada.

Pesquisa feita com usuários dos Parques Biblioteca no final de 2008 revelou que, em sua grande maioria, frequentam o local diariamente e lá permanecem por mais de uma hora. Revelou também que o acesso à Internet é a atividade mais utilizada: oitenta e quatro por cento de seus usuários não tinham acesso à Internet antes da inauguração do espaço. Os usuários também não tinham acesso a programas culturais e artísticos (59\% que sobem para 72,4\% quando se trata de peças teatrais) nem à recreação, sobretudo porque a grande maioria deles residia em áreas com total ausência de políticas públicas. Para uma população de pouco mais de 2.200 mil habitantes, o número de visitantes dos Parques entre janeiro e maio de 2009 é surpreendente: mais de 1.400 mil pessoas. A legitimação do projeto passa a ser um componente determinante da construção processual da cidade como espaço de convivência e de criação de valores democráticos, cotidianamente. A cultura, condição constitutiva da vida social e percebida como força de mudança, tem papel de destaque no projeto de reconstrução de uma cidade democrática que propicie as condições necessárias para que os diferentes sentidos, que produzem os diferentes sujeitos e grupos, possam circular e competir em igualdade de condições na arena pública, como sublinha o colombiano Bernardo Toro.

O olhar externo, de quem busca captar impressões sobre o projeto, percebe que a programação cultural e artística não tem sido devidamente priorizada. A impressão que se tem ao analisar as ações propostas pelos Parques Biblioteca, é que ainda estão bastante centradas na ideia de necessidade, de suprir necessidades que eram urgentes em bairros tão à margem de ações públicas, absolutamente abandonados à própria sorte, inseridos em uma espiral de intensa violência que precisava ser rompida. Entretanto, a cultura insere-se na esfera do desejo, não da necessidade. Quanto à arte, propicia a expansão da sensibilidade, fundamental para a percepção e a compreensão relacional das coisas, ampliando a liberdade, a ousadia, abrindo possibilidades infinitas de se imaginar a sociedade. Seguindo os preceitos de Montesquieu (2005), em seu inacabado verbete para a Enciclopédia iluminista de D’Alembert e Diderot sobre o 'Gosto', entendido por ele como desenvolvimento da sensibilidade, o prazer proporcionado por uma experiência leva o sujeito a outras experiências. A multiplicação de experiências sensíveis amplia a esfera de presença do ser, o maior compromisso que devemos ter conosco. A arte é fundamental para esse desenvolvimento de sujeitos pensantes. Essas esferas precisam ser priorizadas para o adensamento do projeto.

Nessa perspectiva, a política cultural deve proporcionar a vivência de uma infinidade de experiências sensíveis, convocando a sensibilidade individual para a constituição de 
coletividades que consigam desenhar futuros interessantes que se consubstanciem em espaços de convivência. A partir daí, que as pessoas possam inventar a própria vida de múltiplas maneiras e se reconheçam em um projeto de cidade compartilhada, desenvolvendo a ideia de cidade como projeto coletivo em sua acepção mais ampla.

\title{
THE CITY A COLLECTIVE PROJECT: impressions on the Medellín experience
}

\begin{abstract}
This article addresses the possibility of recreating the idea of a city as a collective project based on the impressions of the ongoing Medellin experience in Colombia. It has been able to create a new urban and citizenbased network due to a new conciliation project where culture is the driver.
\end{abstract}

Keywords: City of acknowledgment. Cultural politics. Common culture. Ccivil society. State.

\section{Referências}

Alcaldía de Medellín. Del miedo a la esperanza. Medellín: 2008.

BAUMAN, Z. Confiança e medo na cidade. Rio de Janeiro: Zahar, 2009.

BENKLER, Y. The wealth of network. Yale University Press, 2006 Acessível em cyber.law.harvard.edu/wealth_of_networks/index.php?title=Dowload_pdf_of_the_bookAcess o em janeiro de 2009.

CAETANO, G. 'Cultura, desenvolvimento e política'. IN: Revista Observatório Itaú Cultural/OIC - n.2, (mai./ago.2007). - São Paulo, SP: Itaú Cultural, 2007, p.39-49.

CANCLINI, N. G. Diferentes, desiguales y desconectados: mapas de la interculturalidad. Barcelona: Gedisa, 2004.

CANCLINI, N. G. 'Imaginários culturais da cidade: conhecimento, espetáculo/desconhecimento’. IN: COELHO NETTO, José Teixeira (org). A cultura pela cidade. São Paulo: Itaú Cultural/Iluminuras, 2008, p. 15-30.

COHEN, J. e ARATO, A. Sociedad civil y teoría política. México: Fondo de Cultura Económica, 2001.

DAVIS, M. Planeta Favela. São Paulo: Boitempo, 2006. 
DELEUZE, G. e GUATTARI, F. Mil Platôs. São Paulo: Editora 34, 1996, Volume I.

DUNCAN, G. Violencia y conflicto en Colombia como una disputa por el control del Estado en lo local. Universidad de los Andes. Bogotá. 2004. Documento Cede 2004-11. Acessível em http://ideas.repec.org/p/col/000089/003761.html. Acesso em outubro de 2009.

DUNCAN, G. Del campo a la ciudad en Colombia: la infiltración urbana de los señores de la guerra. Universidad de los Andes. Bogota. 2005. Documento Cede 2005-2.

HAWKES, J. The fourth pillar of sustainability: culture's essential role in public planning. Melbourne: Common Ground/Cultural Development Network. 2001.

LEFEVBRE, H. O direito à cidade. São Paulo: Centauro, 2001.

Lineamientos Político Culturales del Plan de Desarrollo Cultural de Medellín 2009-2020. Alcaldía de Medellín/Fondo Editorial, 2008.

MONTESQUIEU, C. O Gosto. Tradução e pósfácio de Teixeira Coelho. São Paulo: Iluminuras, 2005.

Plan Cultural de Medellín 2010-2020. Sistema Municipal de Cultura de Medellín/Alcaldía de Medellín/Universidad de Antioquia. Apresentação em Power Point. 2009. 